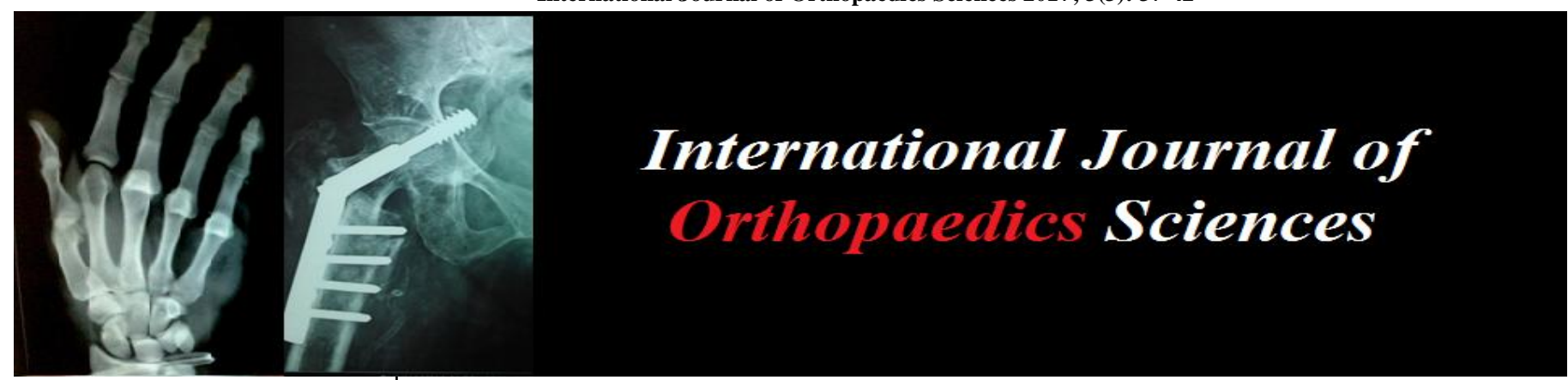

ISSN: $2395-1958$

IJOS 2017; 3(3): 37-42

(C) 2017 IJOS

www.orthopaper.com

Received: 09-05-2017

Accepted: 10-06-2017

\section{GU Kiran}

Assistant Professor, Department of Orthopaedics, SSIMS-RC,

Davanagere Karnataka, India

\section{H Shashidhara}

Assistant Professor, Department of Orthopaedics, SSIMS-RC,

Davanagere Karnataka, India

\section{J Manjunath}

Professor and Head, Department of Orthopaedics, SSIMS-RC,

Davanagere Karnataka, India

Mk Akshay

Resident, Department of Orthopaedics, SSIMS-RC,

Davanagere Karnataka, India

Ashrith Muralidhar

Resident, Department of Orthopaedics, SSIMS-RC,

Davanagere Karnataka, India

Correspondence

H Shashidhara

Assistant Professor, Department

of Orthopaedics, SSIMS-RC,

Davanagere Karnataka, India

\section{A prospective study of functional outcome in intraraticular lower end of humerus fracture treated with dual plating}

\section{GU Kiran, H Shashidhara, J Manjunath, Mk Akshay and Ashrith Muralidhar}

DOI: $\underline{\text { http://dx.doi.org/10.22271/ortho.2017.v3.i3a.09 }}$

\section{Abstract}

Introduction: Lower end of humerus fractures are uncommon and intra-articular in adults, often involve both the medial and lateral columns. Treatment of these fractures is difficult and involves the risk of unfavourable results. Anatomical reconstruction and rigid fixation following early mobilization of the elbow are the prerequisite required for a good clinical outcome. The aim of this study is to evaluate the functional outcome in intra-articular fracture of the lower end of humerus treated with dual plating.

Materials and methods: A prospective study of 20 patients of comminuted intra-articular fracture lower end of humerus treated surgically with, dual plating using standard dorsal approach, olecranon osteotomy with a follow up period of 24 months.

Results: The average age was between $20-54$ years, with mean of 37.5 yaers. 16 cases $(80 \%)$ road traffic accident as major cause of injury. Most of the patients were male 14 (70\%) with dominant limb involvement in $14(70 \%)$ cases. According to MEP score clinical outcome was excellent in $4(25 \%)$, good $10(50 \%)$, fair in $5(20 \%)$ and poor in $1(5 \%)$.

Conclusion: Open reduction and internal fixation with dual plating provides reliable, rigid fixation following an early functional mobilization of the elbow joint and acts as an extrameddulary load bearing device, stabilizing fracture fragment and ensuring bony union in fracture lower end of humerus with intraarticular extension.

Keywords: Lower end of humerus, Dual plating, internal fixation, Olecranon osteotomy

\section{Introduction}

Lower end of humerus fractures make up 0.5 to $2 \%$ of all fractures, but up to $30 \%$ of fractures involving the elbow joint. In adults, most of the lower end humerus fractures are intra-articular and involve both the medial and lateral columns. The distribution of lower end humerus fractures follows a bimodal age distribution. High energy injuries tend to occur among younger patients, while low-energy injures are more common in older patients. Understanding the anatomy of the lower end humerus is critical to effective treatment of lower end humerus fractures. Divergent medial and lateral columns of bone support the lower end of humeral articular surface in an inverted-Y configuration. The traditional classification of lower end humerus fractures has centered around the terminal ends, or the condyles of the humerus. When discussing intra-articular fractures of the lower end of humerus, the term "condyle" is converted to "columns" for the sake of classification. Several classification systems for intraarticular both column fractures of the lower end of humerus have been pro-posed. Riseborough and Radin 1 described 4 types of intercondylar "T-type" distal humerus fractures: Type 1 was a non-displaced fracture, Type 2 was displaced but without rotation of the fragments, Type 3 includes fragment rotation, and Type 4 involved severe comminution. Although initially relevant for its descriptive value, these classifications proved inadequate in reliably describing the fracture and directing treatment as these injuries were more frequently being treated operatively. The Orthopaedic Trauma Association's alpha-numeric system, assigned three main types: Type A (extra-articular), Type B (partial articular), and Type C (complete articular). The OTA system's clinical application is limited and is hindered by poor interobserver reliability beyond identification of the basic three types. 
The indication for non-operative treatment of distal humerus fractures is limited and primarily involves patients with very low demand or in poor health. The risk of fracture displacement, mal union, and non-union is high with nonoperative treatment, due to the characteristic intra articular involvement, and poor control of fracture fragments when closed treatment is done, hence we typically treat these fractures operatively. Different types of implants like $\mathrm{K}$ wires, $4 \mathrm{~mm}$ cancellous screws, $3.5 \mathrm{~mm}$ recon plates and one third tubular plates are being used during operative procedure. Precontoured column specific locking plates useful in osteoporotic bone fixation. Several variables are important in successful management of these fractures: restoration of articular congruity, secure bony fixation, achievement of bony healing, maintenance of a functional range of motion, and avoidance of complications such as hypertrophic ossification and ulnar neuropathy. The objective of this study was to evaluate the clinical outcome in intra articular lower end of humerus fractures treated surgically with dual plates.

\section{Patients and methods}

This is a prospective type of study of 20 cases of lower end fracture humerus with inter condylar extension treated surgically with dual plating which were admitted To ssimsrcdavanagere, karnataka, between November 2012 to October 2015. All the patients of lower end humerus fracture with age between 20 to 54 years with medical fitness for surgery were included in the study. Patients medically unfit for surgery and those not willing for surgery, Compound fractures of the lower end of humerus, lower end of humerus fractures in children were excluded from study. All the patients who attended to casuality and orthopaedic OPD examined to rule out any associated injuriesAll the patients subjected for $\mathrm{X}$ rays of elbow joint antero posterior and lateral views to confirm the fracture and above elbow POP slab applied. After surgical profile screening patients were posted for surgery electively.

\section{Operative technique}

Patients were positioned in the lateral decubitus position with arm rest for the operated site. The arm and forearm were washed with soap and water. Tourniquet was applied on the proximal arm. Skin was prepared by povidone iodine $(10 \%$ $\mathrm{v} / \mathrm{v})$ solution and the operating field from mid arm to mid forearm was draped. A posterior midline incision $5 \mathrm{~cm}$ proximal and distal to the olecranon was made and fullthickness flaps retracted medially and laterally. Ulnar nerve identified and retracted medially with a long gauze. Laterally, the triceps was dissected off the lateral intermuscular septum. The interval between the triceps and anconeus muscles was developed to expose the jointA chevron osteotomy over the olecranon was made with an oscillating saw and completed with an osteotome. The triceps were retracted with the olecranon proximally. The fracture edges were cleaned with normal saline. The fracture fragments were reduced and stabilised with bone clamp and were provisionally fixed with Kirschner wires. Then rigid fixation was achieved by insertion of lag screws and variable numbers of locking screws which were inserted after drilling the bone through the plate and bone surface by motorized power drill or hand-drill. The plates were placed in $90-90$ position. The olecranon osteotomy was repaired with stainless steel wires $(20 \mathrm{~mm})$ using tension band principle. The skin wounds were closed over a negative suction drain after thorough washing with copious amount of sterile saline solution and sterile dressings applied over the limb. A posterior above elbow pop slab applied in extension for three days. The operated limb was kept elevated. During this time passive and active movements of the fingers were encouraged. Patients received parenteral third generation cephalosporin for five days which was then changed to appropriate oral formulation from the sixth day and continued for another seven days. Antiinflammatory analgesics and other supportive measures were also given as per individual requirements. check X-ray (AP/Lat) of the limb was taken. Active movements of the limb was started and continued from immediate post operative day. Skin sutures were removed on the tenth post-operative day and patients were discharged and some patients were discharged after few post-operative days and were called in the OPD for suture removal

Table 1: Technical Objectives for Fixation of lower end Humeral Fractures

\begin{tabular}{|c|}
\hline 1. Every screw should pass through a plate. \\
\hline 2. Each screw should engage a fragment on the opposite side that is also fixed to a plate. \\
\hline 3. As many screws as possible should be placed in the distal fragments. Each screw should be as long as possible. \\
\hline 4. Each screw should engage as many articular fragments as possible. \\
\hline 5. Plates should be applied such that compression is achieved at the supracondylar level for both columns. \\
\hline 6. Plates used must be strong enough and stiff enough to resist breaking or bending before union occurs at the supracondylar level. \\
\hline 7. From Sanchez-Sotelo J, Torchia ME, O'Driscoll SW: Principle-based internal fixation of distal humerus fractures, Tech Hand Upper \\
Extremity Surg 5:179, 2001
\end{tabular}

\section{Results}

The present study consists of 20 cases of lower end humerus fracture with inter condylar extension treated by open reduction and internal fixation with Dual plating $(3.5 \mathrm{~mm}$ reconstruction plate and 1/3rd tubular plate) from November
2012 to October 2015.

In mode of injury, 14 cases $(70 \%)$ were due to road traffic accident (RTA) and 5 cases $(30 \%)$ were due to direct fall injury, 1 case of assault (Table 1). 
Table 2

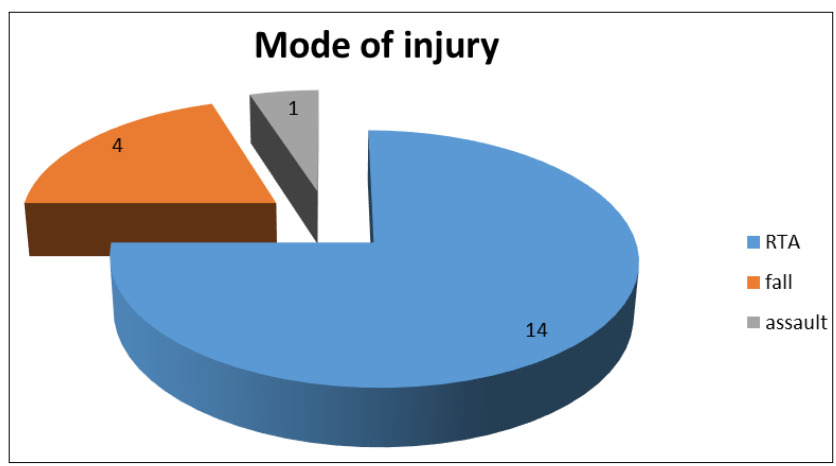

Right upper limb was involved in 14 (70\%) cases and left upper limb in 6(30\%) cases (Table 2)

Table 3

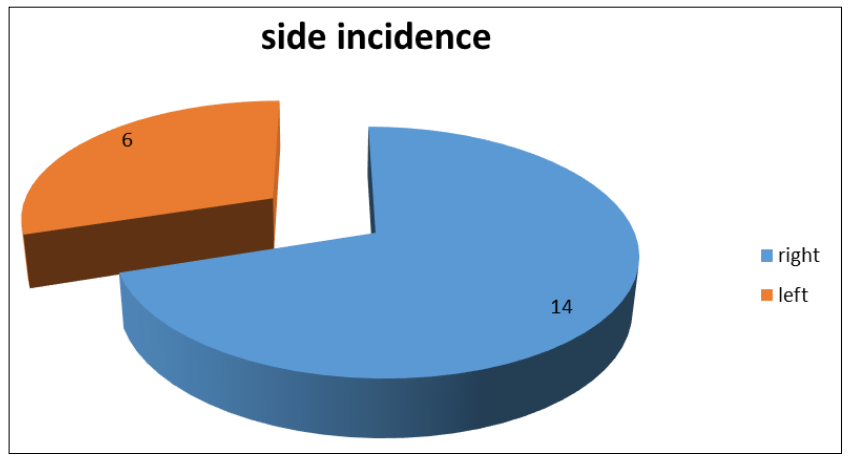

In sex distribution, there were 14 (70\%) males and $6(30 \%)$ females (Table 3).

Table 4

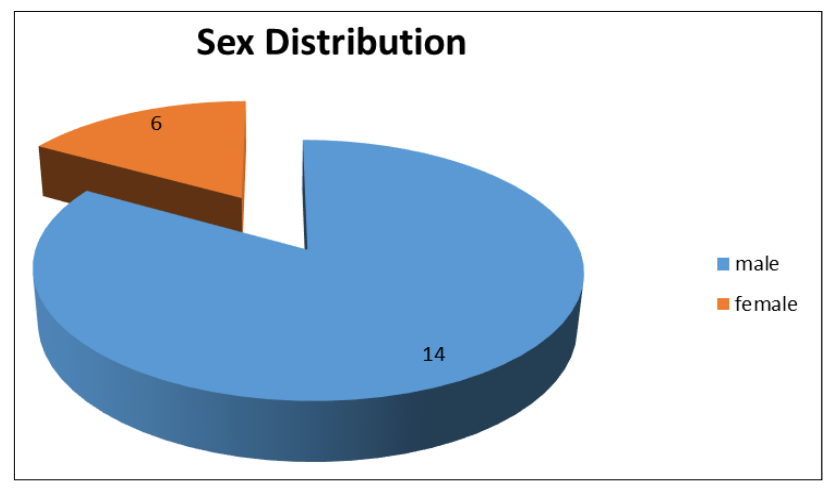

All the cases were operated electively on regular operation theatre days. In the post - operative period one patient developed superficial wound infection in which suture removal was delayed. Heterotropic ossification with elbow stiffness occurred in three patient. Delayed union at osteotomy site identified in one patient. Hand wasting in one patient. In our study, radiological union was seen at 4 months to 7 months. Average duration radiological union was 16.4 weeks.

Table 4

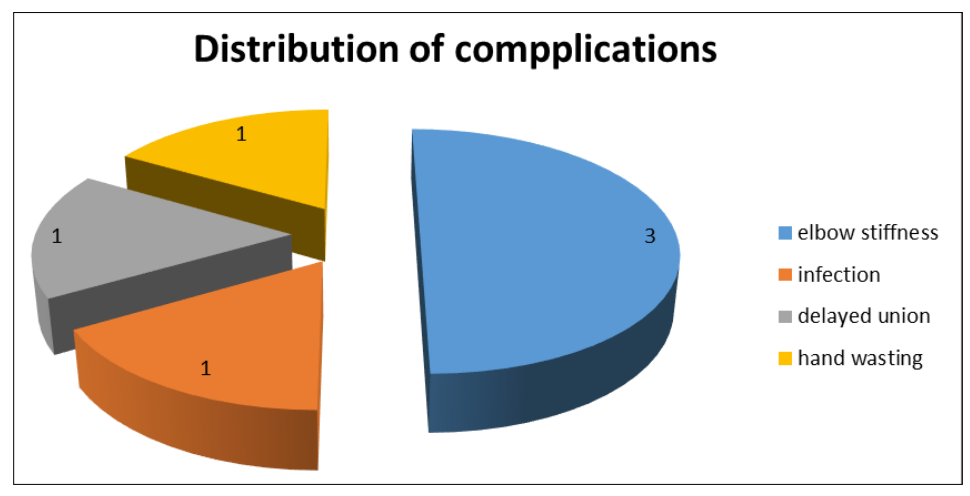




\section{Mayo elbow performance score}

\begin{tabular}{|c|c|c|c|}
\hline & MEP score & number & Percentage \\
\hline Excellent & $91-100$ & 5 & $25 \%$ \\
\hline Good & $75-90$ & 10 & $50 \%$ \\
\hline Fair & $60-74$ & 4 & $20 \%$ \\
\hline poor & $<60$ & 1 & $5 \%$ \\
\hline
\end{tabular}

\section{Discussion}

In adults, most of lower end humerus fractures are intraarticular and involve both the medial and lateral columns. Due to the characteristic intra articular involvement, displacement, and poor control of fracture fragments with closed treatment, we typically treat these fractures operatively. The goal of treatment is restoring painless and functional elbow in a fractured lower end humerus which requires anatomical reconstruction and stable fixation. Though parallel plating proposed by O'Driscoll SW is more biomechanically stable than perpendicular plating technique, we did perpendicular plating technique as it requires less soft tissue dissection and time duration, technically less demanding and stability achieved by this technique is enough for bone union and early rehabilitation. 2 In our study, we treated all 20 cases with open reduction and internal fixation with dual plating in 90-90 configuration i.e., one plate on medial boarder and another on posterior surface of lateral column. In our study, there were 14 (70\%) males and 6 (30\%) females comparable to study by Henley et al and in Wang et al studies showed $60 \%$ males and $40 \%$ females.3,4 In our study 14 cases $(70 \%)$ were due to road traffic accident (RTA) and 5 cases $(30 \%)$ were due to direct fall injury comparable to Henley et al study showed $61 \%$ cases due to RTA and $39 \%$ cases due to direct injury. 3 Gabel et al reported $100 \%$ cases due to direct injury. In our study incidence of right and left upper limb involvement comparable to other studies by Jupiter et al. Average MEP score was 84, similar to study done byAtalar AC et al evaluating the functional outcome of complex lower end humerus fractures in 21patients the mean MEP score to be 86.1.7 The complications noted in our study are hard ware protrusion at tension band wiring site in two patients and we managed with early removal of protruding $\mathrm{K}$ wires from TBW site after union at osteotomy site. Hypertrophic ossification with elbow stiffness occurred in one patient, managed with regular physiotherapy. Delayed union at osteotomy site identified in one patient.

\section{Case scenario}

Preop and postop with follow up xrays
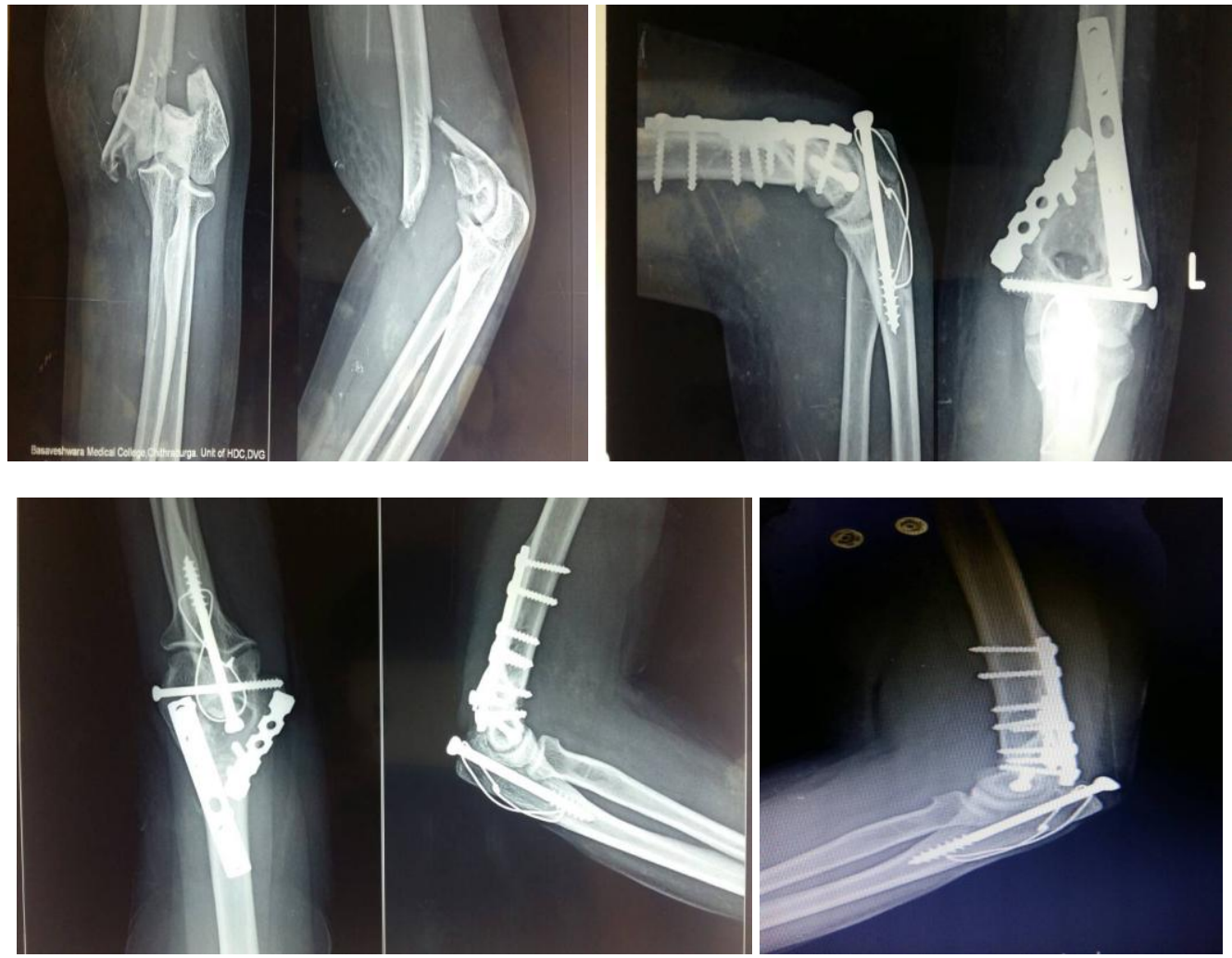

\section{Functional outcome}
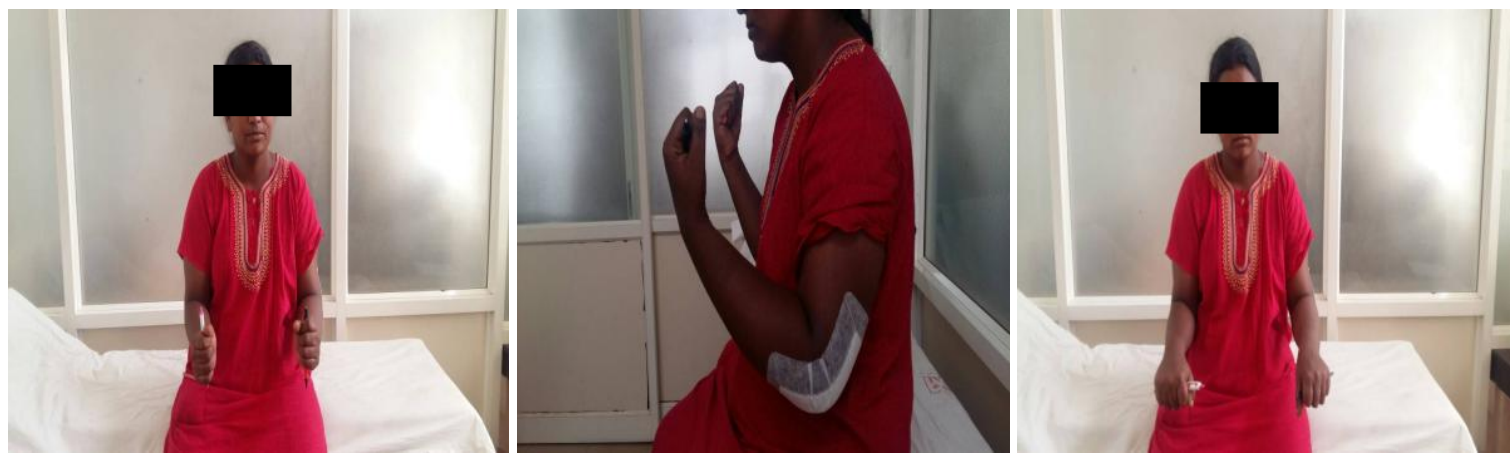

$\sim 40 \sim$ 

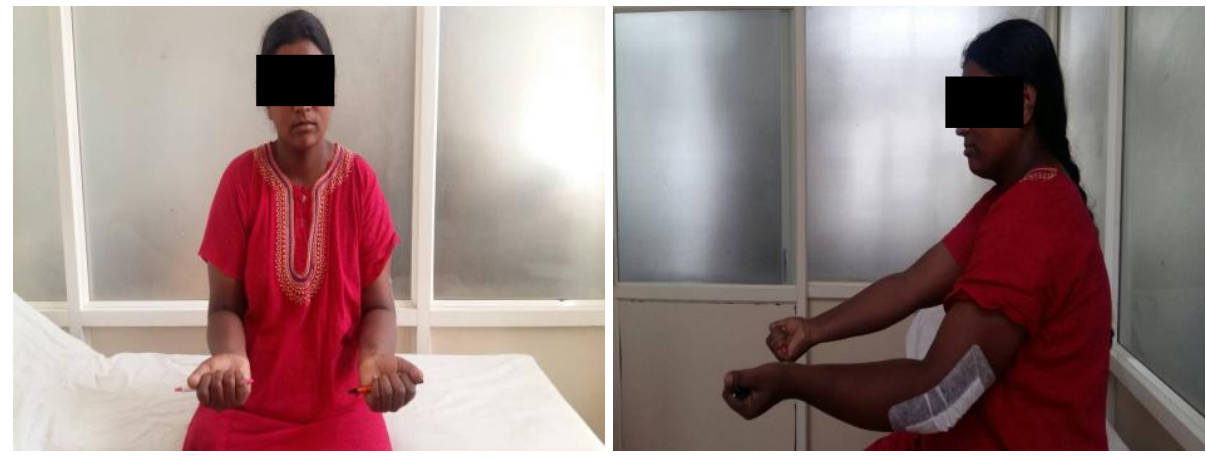

\section{Case senario}
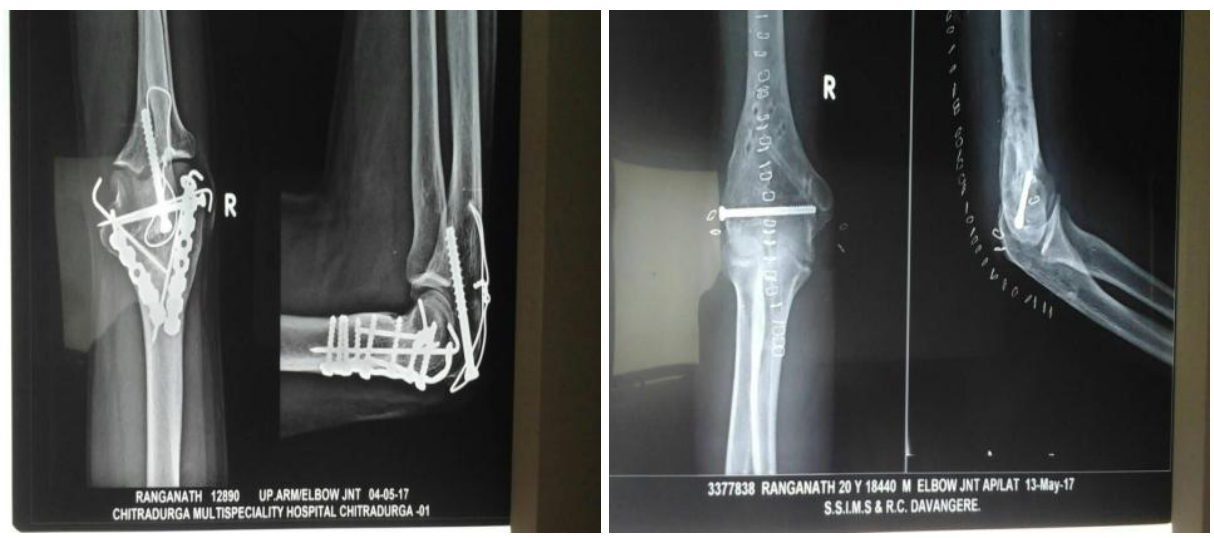

\section{Functional outcome}
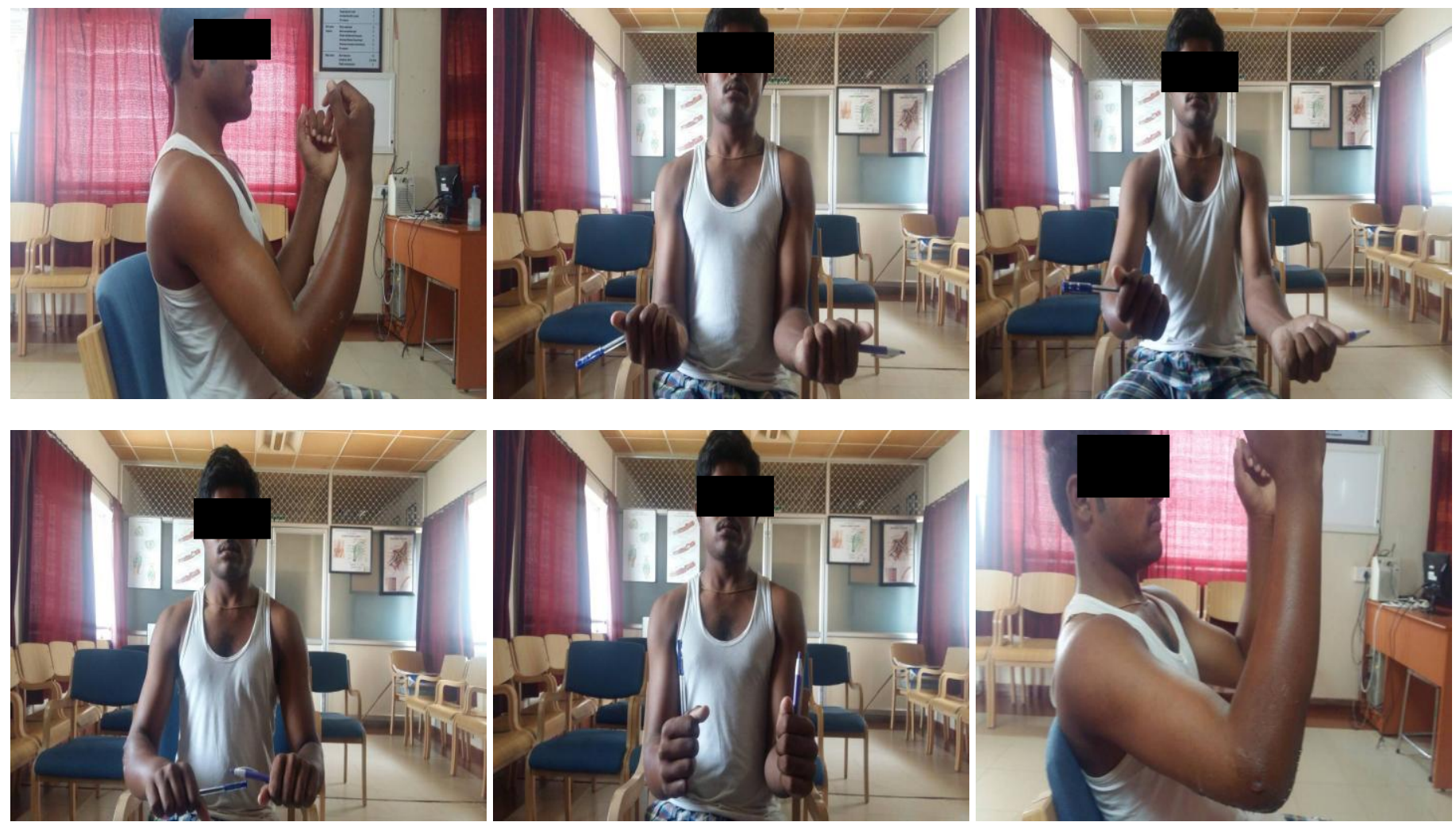

\section{Conclusion}

Lower end humerus fractures known for their complex nature and technical difficult in surgical management. Proper anatomical articular reconstruction, stable fixation and early post-operative physiotherapy help in restoring painless and functional elbow

\section{References}

1. Riseborough EJ, Radin EL. Intercondylar T fractures of the humerus in the adult. A comparison of operative and non-operative treatment in twentynine cases. J Bone Joint Surg Am. 1969; 51(1):130-41.

2. O'Driscoll SW. Management of the smashed distal humerus. Orthop Clin N Amer. 2002; 33:19-33.

3. Henley MB. Intraarticular distal humerusfracturesin 
adults. Orthop Clin North Am. 1987; 18(1):11-23.

4. Wang KC, Shih HN, Hsu KY, Shih CH. ntercondylar fractures of the distal humerus: Routine anterior subcutaneous transposition of the ulnar nerve in a posterior operative approach. J Trauma. 1994; 36(6):7703.1. Kuntz Jr, David G, Baratz ME. Fractures of the elbow. OrthopClin North Am Jun. 1999; 30(1):37-61.

5. Gabel GT, Hanson G, Bennett JB, Noble PC, Tullos HS. Intra articular fractures of the distal humerus in the adult. Clin Orthop Relat Res. 1987; 216:99-108.

6. George S. Athwal Fractures of the distal humerus. Chapter-33 in Rockwood and Green's fractures in adults. 7th Edn. Lippincott Williams and Wilkins. 945-998. 3. Robinson CM, Hill R, Jacobs N, Dall G, Brown C. Adult humeral metaphyseal fractures. Epidemiology and results of treatment. J Of Orthop Trauma. 2003; 17:38-47.

7. Galano GJ, Ahmed AS, Levine WN. Current treatment for bicolumnar distal humerus fractures. J Am Acad Orthop Surg. 2010; 18:20-30. 5.

8. Nauth A, McKee MD, Ristevski B, Hall J, Schemitch EJ. Current concepts review. Distal humerus fractures in adults. J Bone Joint Surg (Am). 2011; 93:686-700.

9. Horlohe KHS, Bonk A, Wilde P, Becker L, Hoffmann R. Promising results after the treatment of smile and complex distal humerus type $\mathrm{C}$ fractures by angular stable double plate osteosynthesis. Orthop Traumatol Surg Res. 2013; 99:531-541.

10. Gupta R, Khanchandani P. Intercondylar fractures of the distal humerus in adults. A critical analysis of 55 cases. Injury. 2002; 33:511-515.

11. Korner J, Lill H, Muller LP et al. Distal humerus fractures in elderly patients. Results after open reduction and internal fixation. Osteoporos Int. 2005; 16:73-79.

12. Danny Goel P, Jeffery Pike M, George Athwal S. Operative techniques in orthopaedics. Oper Tech Orthop. 2010; 20:24-33. 